\title{
Uplift of the Miyako Knoll on a landward trench slope of the Japan Trench, off Miyako, NE Japan
}

\section{Kiichiro Kawamura*, Hideki Hamamoto**, Makoto Yamano**, Tada-nori Goto***, Kiyoshi Baba** and KR08-10 Shipboard Scientists****}

Received October 3, 2008

Accepted November 10, 2008

* Fukada Geological Institute, 2-13-12 Honkomagome, Bunkyo-ku, Tokyo 113-0021, Japan.

** Earthquake Research Institute, The University of Tokyo, 1-1-1 Yayoi, Bunkyo-ku, Tokyo 113-0032, Japan

*** Institute for Research on Earth Evolution, Japan Agency for Marine Science and Technology (JAMSTEC), 2-15 Natsushina-cho, Yokosuka, Kanagawa 237-0061, Japan.

**** Makoto Harada (Tokai University), Yoshifumi Kawada, Noriaki Sakurai (JAMSTEC), Tomoko Hanyu (The Graduate University for Advanced Studies), Satomi Minamizawa (Nippon Marine Enterprise Co. Ltd.), Ei Hatakeyama, Naotaka Togashi, Akira So (Marine Works Japan Co. Ltd.)

Corresponding author, K.Kawamura, fgi@fgi.or.jp

Fig. 1. A: Location of the study area. The map was drawn based on a data set of ETOPO2 from NOAA using GMT ver. 3. B: Detailed bathymetric map of the study area. Open stars and solid lines show locations of the piston coring sites and survey lines of sub-bottom profiler, respectively. The map was drawn based on a data set of the JODC-Expert Grid data for Geography $-500 \mathrm{~m}$. Contour lines of $A$ and B are $1000 \mathrm{~m}$ and $100 \mathrm{~m}$ intervals, respectively.
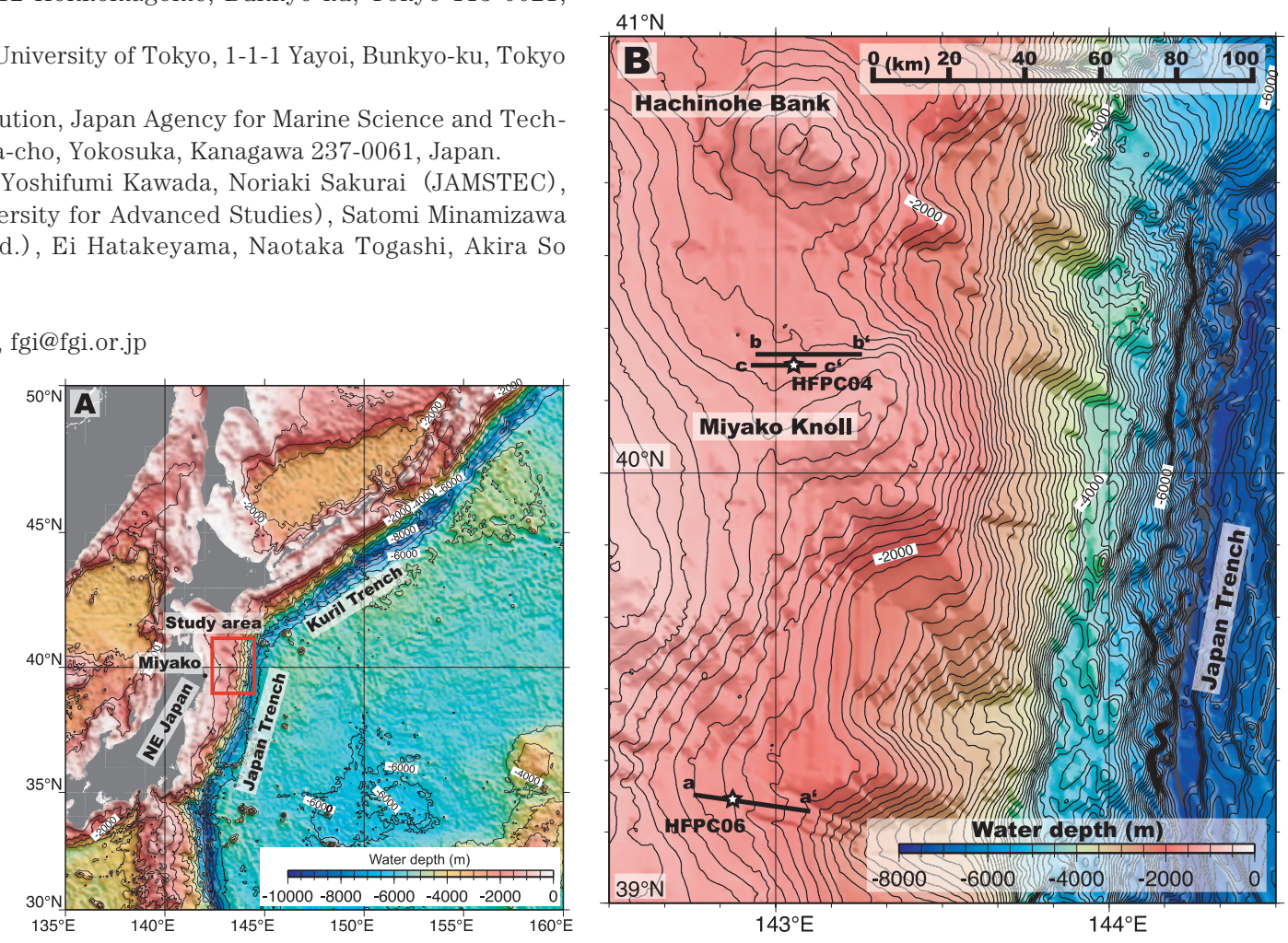

Sub-bottom profiler (hearafter SBP) images and piston core samples were collected from the south and north of the Miyako Knoll on the landward wall of the Japan Trench during the Cruise KR08-10 of R/V KAIREI in September, 2008, off Miyako, northeast Japan (Fig. 1). The SBP image in a gentle trench slope at $\sim 100 \mathrm{~km}$ south of the Miyako Knoll (Fig, 2.A) shows that slope sediment layers (predominantly silty clay; Fig. 3) are thickening toward the lower slope, whereas that in north foot of the Miyako Knoll (Fig. 2.B) indicates that slope sediment layers (mainly sandy clay; Fig. 3) are thinning progressively toward the Miyako Knoll due to erosion of seafloor layers. This erosion is thought to be resulted from the Quaternary uplift of the Miyako Knoll (Iwabuchi et al., 1996).

\section{Acknowledgment}

The authers gratefully acknowledge Mr. Toru Takahashi (Fukada Geological Institute), Dr. John E. (Jed) Damuth (University of Texas), Dr. Osamu Takano (JAPEX) and an anonymous reviewer for comments and suggestions.

\section{Reference}

Iwabuchi, Y., Izumi, N., Ogawa, Y. and Kaiho, Y., 1996, Topography and geology of landward slope of the Japan Trench, off Sanriku. JAMSTEC J. Deep-Sea Res., 12, 23-34 (Japanese with English abstract)

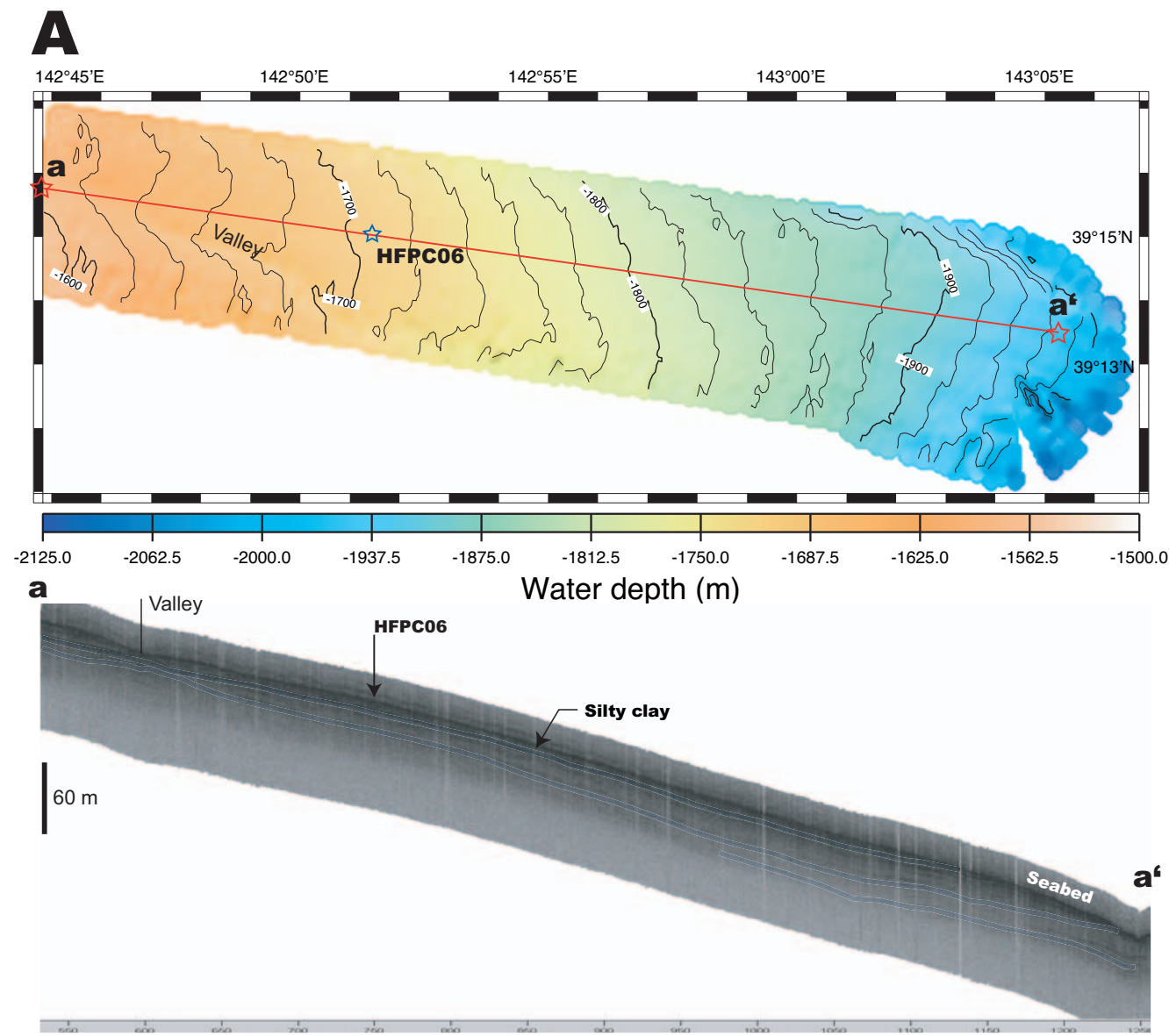

Fig. 2. See caption in next page. 


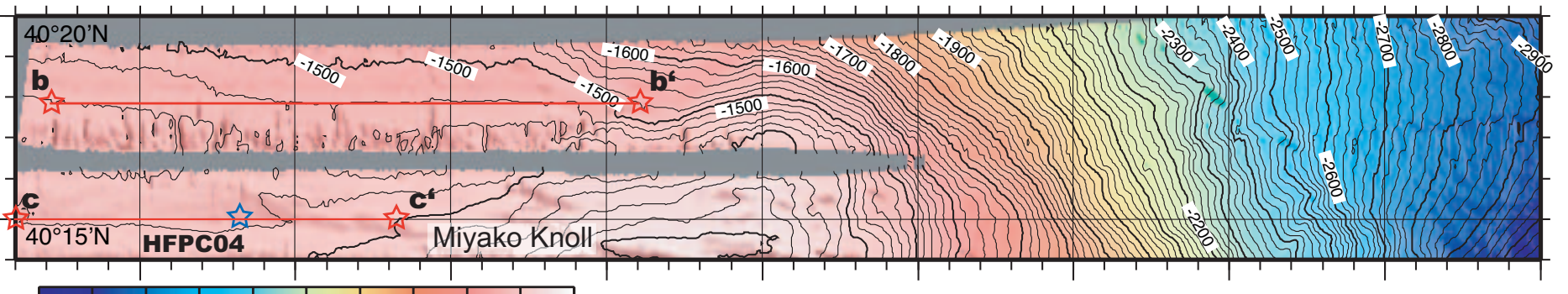

$-3200-3000-2800-2600-2400-2200-2000-1800-1600-1400-1200$

b depth in Meters

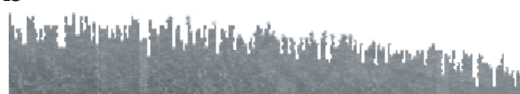

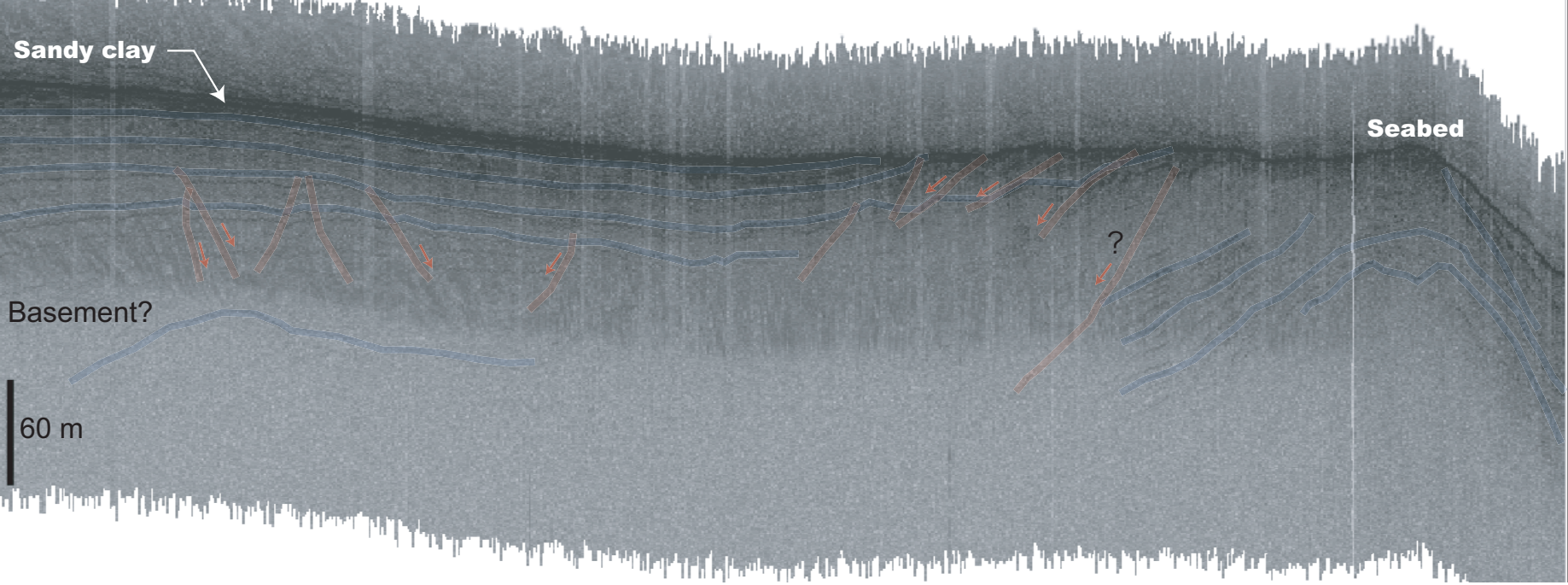

HFPCO4
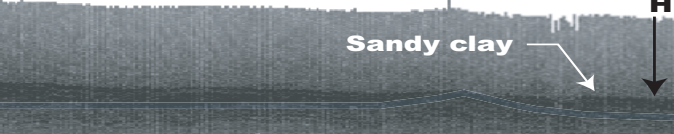

Basement?

$60 \mathrm{~m}$

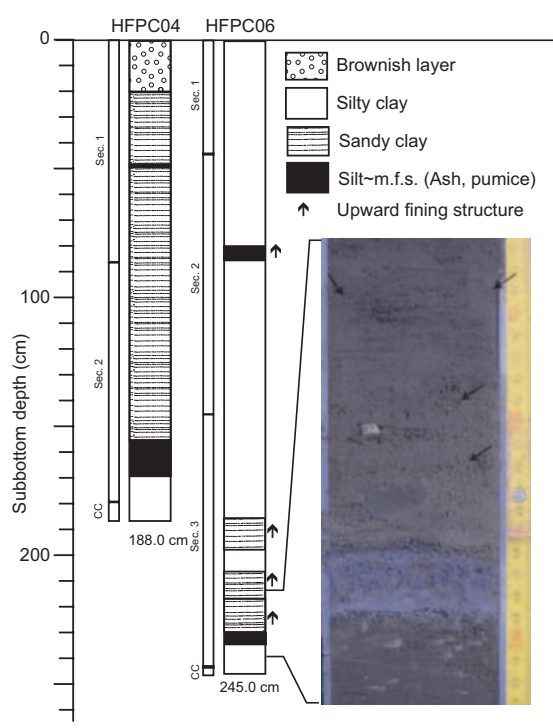

Fig. 2. Detailed bathymetric maps and sub-bottom profiling images of a portion of the landward slope south of the Miyako Knoll (A) and north of the foot of the Miyako Knoll (B). In the bathymetric maps, open red stars and solid red lines indicate the SBP survey line, and open blue stars are coring sites. In the SBP images, red lines and red arrows indicate faults and slip direction of faults, respectively. Blue lines show reflectors.

Fig. 3. Photographs and lithologic columns of Piston cores HFPC04 and 06. HFPC04 on north foot of the Miyako Knoll ( $\left.40^{\circ} 15.0200 ' N, 143^{\circ} 03.5010^{\prime} \mathrm{E}\right)$. The water depth was $1425 \mathrm{~m}$. HFPC06 collected from the trench slope in south of the Miyako Knoll $\left(39^{\circ} 14.9895\right.$ 'N, $142^{\circ} 51.0745$ 'E). The water depth was $1697 \mathrm{~m}$. Those coring locations are shown in Figs. 1 and 2. HFPC04 is mostly bioturbated sandy clay with diatoms, whereas HFPC06 is composed of predominantly bioturbated silty clay with diatoms interbedded with three turbidite layers including many foraminifers (black arrows in the inset photo), which may be derived from the upper slope. 